\title{
El corso como servicio a la Corona y oportunidad de negocio para los particulares. La Escuadra de Mallorca (1660-1684)*
}

\author{
- Gonçal López NAdAL \\ - Antònia Morey Tous \\ Universitat de les Illes Balears
}

\section{Presentación}

El objetivo de este artículo es profundizar en el conocimiento de la historia económica de la empresa preindustrial a través del estudio de una compañía corsaria que, como era habitual en su ámbito, tuvo un carácter efímero y surgió con una finalidad concreta: auxiliar a la marina real. Desde esta perspectiva ejemplifica la simbiosis entre intereses generales y particulares, tan frecuente durante la Edad Moderna, y permite profundizar en el análisis de una oportunidad de negocio propia del período. ${ }^{1}$ El cometido de la empresa era ejercer el corso contra los enemigos políticos del rey y, en este caso en particular, contra Francia con motivo de la crisis que supuso la sublevación de Mesina, protagonizada en 1674 por una de las dos facciones enfrentadas en Sicilia. ${ }^{2}$ Dicho de otra manera, se trataba de hacer una campaña marítima contra el enemigo en el sur de Italia, uno de los territorios de la Italia española que desde la época de Fernando el Católico había sido objeto de confrontación y cuyo dominio fue considerado, durante gran parte de la Edad Moderna, como el paso previo para alterar la hegemonía española en Europa. Si bien, como es sabido, la decadencia española se empezó a evidenciar mucho antes con las insurrecciones catalanas y portuguesas de 1640, el

* Agradecemos a los evaluadores anónimos, en particular al segundo, las puntualizaciones realizadas, las cuales en la medida de lo posible hemos incorporado al texto.

1. Véanse, para una primera aproximación a esta empresa, dos comunicaciones anteriores: López Nadal (2006) y Llompart, Morey y López (2016).

2. Sobre Mesina y la defensa de las provincias italianas, resultan de consulta obligada las investigaciones de Ribot García (1995, 2002).

Fecha de recepción: abril 2017

Versión definitiva: noviembre 2017

Revista de Historia Industrial

$N^{\circ}$ 73. Año XXVII. 2018 
reconocimiento en 1650 de la independencia de las Provincias Unidas de Holanda, la independencia definitiva de Portugal en 1652 y la cesión a Francia, a raíz de la Paz de los Pirineos de 1659, de los territorios del Rosellón y la Cerdaña.

La formación de la Escuadra de Mallorca se engloba, pues, en la etapa de declive del imperio (durante el reinado de Carlos II), cuando España se encontraba en guerra (dentro del contexto de la Gran Alianza de La Haya) con la Francia expansionista de Luis XIV, que en 1672 había invadido Holanda y que en 1675 no desaprovechó tampoco la oportunidad que le brindó la insurrección de Mesina para enviar una flota a Sicilia en apoyo de los sublevados. En dicha etapa, como se desprende de la bibliografía reciente sobre la historia militar hispánica, el corso fue especialmente incentivado debido a la decadencia naval española y al auge experimentado por otras potencias como Inglaterra o Francia. ${ }^{3}$ Desde esta perspectiva, el estudio que nos ocupa puede resultar igualmente de interés para ilustrar los esfuerzos del monarca para prolongar la pervivencia del imperio. ${ }^{4}$ Todo ello sin olvidar, no obstante, que el corso, además de una estrategia militar, constituyó sobre todo una oportunidad de negocio tanto para los particulares como para la propia monarquía que, a través del denominado quinto real, tenía derecho a participar de los beneficios generados por la venta de las capturas enemigas.

Sobre esta actividad interesa recordar que es un fenómeno marítimo en el que converge una triple dimensión operativa. ${ }^{5}$ Puede considerarse como una actividad militar en la que los particulares (de aquí su calificación inglesa como Privateering) auxilian a las marinas oficiales; como un vehículo mercantil que ofrece, mediante la captura de la embarcación enemiga, la posibilidad de ejercer un «comercio forzado» ${ }^{6} \mathrm{y}$, por supuesto, como un instrumento para llevar a cabo la «guerra santa». En el Mediterráneo, ámbito en el que

3. Para una visión de conjunto sobre las armadas durante la Edad Moderna: Fernández Duro (1972), Olesa Mundo (1968), Salvá (1944) y Fernández Almagro (1941). Sobre las armadas en el Mediterráneo, destaca el artículo de síntesis de Bunes (2006), p. 97.

4. Una línea de investigación que defienden, entre otros, Storrs (2003), Martínez Ruiz (2008), Contreras Gay (2003), Rodríguez Hernández (2007), el ya citado Ribot García (2002) y Saavedra (2006) y Pi Corrales $(2001,2006)$. Así mismo, la proliferación de compañías corsarias durante el reinado de Carlos II está documentada en distintos territorios. Por ejemplo, en Galicia (Saavedra 2006, 2011, 2013) y el País Vasco (Guevara, 2006, y Otero Lana, 1999, 2006).

5. A pesar del tiempo trascurrido, y aunque con matices, continúan siendo de interés los planteamientos de Braudel (1976), vol. 2, pp. 190-212. Igualmente los de Fontenay y Tenenti (1975), pp. 8-136, Tenenti (1985), Bono (1964, 1993) y Verge-Franceschi (2000). Así mismo, los dos volúmenes del Course et Piraterie con motivo del xve Colloque International des Sciences Historiques (San Francisco, agosto de 1975). Con posterioridad, algunos de los contenidos presentados en dicho coloquio fueron ampliados por Toussaint (1978), Bromley (1987), Starkey, de Moor \& Heslinga (1997) y Pennell (2001), entre otros.

6. López Nadal (1986), pp. 15-16. 
actúa la empresa que nos ocupa, ${ }^{7}$ el período álgido del corsarismo transcurre entre las últimas tres décadas del siglo XVI y el primer cuarto del siglo XVII. ${ }^{8}$

\section{Orígenes de la empresa y fuentes para su estudio}

Por el momento no estamos en condiciones de fijar el año de constitución de la Escuadra de Mallorca. Sin embargo, nos consta, por trabajos anteriores, que su período de actividad es muy concreto (1660-1684) y que sus orígenes están a la vez muy relacionados con una iniciativa similar que propició, al parecer, grandes beneficios a un grupo de armadores mallorquines durante los años cuarenta y cincuenta del siglo XVII con motivo de la sublevación conocida como Guerra dels Segadors o rebelión de los catalanes (1640-1652) y de la prosecución de la contienda contra Francia - Guerra del Rossellóque terminó con la Paz de los Pirineos (1659). Esta, al igual que cualquier otro tratado de paz o tregua, supuso la paralización de las actividades corsarias, muy en particular la que presuponía la depredación de los mercantes del Rey Cristianísimo. No obstante, la frágil estabilidad y la reanudación del conflicto político propició nuevos armamentos y la consiguiente puesta a punto de la organización corsaria mallorquina. A principios de 1661, por ejemplo, se tiene constancia del armamento del Águila Doble por parte de diversos capitanes, mercaderes y miembros de la nobleza, algunos de los cuales figurarán entre los firmantes de los futuros acuerdos de la Escuadra de Mallorca de 1674 y $1677 .{ }^{10} \mathrm{El}$ mes de junio de este mismo año, concretamente los días 18 , 20, 22 y 26, constan cuatro certificados sobre el armamento de esta misma nave (capitaneada por Miquel Rovira) con mención explícita de sus financieros y de las cantidades invertidas respectivamente. El total de las inversiones alcanzaba los 2.998 pesos de a ocho y sus armadores volvían a ser el capitán Jaime Canals, el mercader Juan Bautista Suñer y los nobles señores Juan Miquel Sureda y Ramón Despuig, conde de Montenegro y de Montoro. ${ }^{11}$ Nos

7. Sobre el corso como un fenómeno intrínseco del Mediterráneo, véase Fontenay (1986), pp.116-120 y sobre el corsarismo no mediterráneo, Crowhurst (1987), pp. 311-322.

8. Concretamente, desde el final de la batalla de Lepanto (1571) hasta la firma de la Paz de Utrecht (1713). Su persistencia posterior, más bien a la baja, se explica por la alianza entre franceses y españoles. Sin embargo, no será hasta la ocupación de Argelia por los franceses en 1830 cuando perderá su razón de ser. En 1856, el Tratado de París sellará definitivamente el fin del corso como institución marítima (López Nadal, 1986), pp. 19-20.

9. Entonces, los corsarios mallorquines forman la Escuadra de Bergantines de Mallorca (López Nadal, 1978, 1981). Véase la aportación reciente de Deyá (2010) y el trabajo más general de Espino (1999).

10. Se trata del capitán Jaime Canals, el mercader Juan Bautista Suñer y los nobles señores Juan Miguel Sureda y Ramón Despuig, conde de Montenegro y de Montoro. En total invierten la cantidad de 5.000 pesos de a ocho (equivalentes a unas 5.650 libras mallorquinas).

11. ACV. Negocis per Mar de los Sureda, sin foliación. 
consta, así mismo, que pocos días después, el 5 de julio, el notario Lorenzo Busquets rubrica los preparativos de la Escuadra de Mallorca compuesta entonces por tres navíos. Además de la antes mencionada Águila Doble, registrada ahora como almiranta, figuran la capitana San Antonio y El Beato Caetano, y como gobernador de la Escuadra Pedro Flexes, piloto a la vez de la capitana, mientras que las otras dos eran pilotadas, respectivamente, por Miquel Rovira y Juan Bautista Delopino. ${ }^{12}$

Las informaciones que poseemos sobre las actividades corsarias mallorquinas durante los años sesenta del siglo XVII son escasas. El traslado de la guerra naval a las costas portuguesas y la calma frente a los franceses - ya que el único conflicto armado apenas dura un año (1667-1668) - depararon una cierta detención del corso isleño, más proclive a las actuaciones en el mar interior que a sus incursiones ponentinas. De hecho, hasta prácticamente 1674 no volveremos a tener noticias de la Escuadra. La guerra de Holanda (1674-1678) y, en su plasmación meridional, la rebelión «antiespañola» de Mesina ${ }^{13}$ representa, como decíamos, el caldo de cultivo de sus actuaciones. De estas se ha conservado abundante documentación en los archivos públicos (fundamentalmente los de la Corona de Aragón y del Reino de Mallorca) y en los archivos privados de algunos de sus inversores. Entre estos últimos, merecen una especial atención los papeles relativos a las actividades corsarias de dos de los principales armadores: los ya citados Ramón Despuig, conde de Montenegro y de Montoro, y Juan Miguel Sureda, ambos pertenecientes al brazo noble y destacados terratenientes. ${ }^{14}$ Entre la numerosa documentación conservada en sus archivos, relacionada sobre todo con la gestión de la propiedad inmobiliaria, destacan algunos papeles y legajos que ilustran cómo, a pesar de que los miembros del estamento nobiliario tuvieran prohibido el ejercicio de la mercadería, ${ }^{15}$ intervinieron de forma activa en «negocios marítimos». Uno de estos documentos es el excepcional dossier conservado en el archivo particular de Juan Miguel Sureda que lleva por título Libre del Gasto del Armament de la nostre Esquadra per lo servici ha de fer en servici de el Rey nostre Sr que Deu guarde per lo de la guerra de Messina de la qual es Governador lo Capn Pere Flexas en lo any 1677. ${ }^{16}$

12. El coste suma un total de 35.467 pesos de a ocho y 4 reales (alrededor de 40.078 libras mallorquinas). ARM. B-1.685, f. 168.

13. Véanse Ribot (1983) y Atti del Convegno Storico (1979).

14. Sobre el particular, véanse Montaner (1978, 1984 y 1990), Montaner y Le-Senne (1979-80) y Morey $(1992,2018)$.

15. Montaner (1978) subraya que, dado que la alta nobleza tenía prohibido ejercer el comercio, formaba a menudo compañías con mercaderes para ocultar dicha actividad. Un punto que le rebate, en parte, Bibiloni (1995) en una monografía sobre el comercio exterior mallorquín durante la segunda mitad del siglo XVII.

16. ACV. Legajo 74/10. Agradecemos a P. Montaner que nos haya facilitado su consulta. 
En el archivo del conde de Montenegro, el tercer mayor inversor de la Escuadra, ${ }^{17}$ se conservan así mismo numerosos documentos de características semejantes al registro anteriormente descrito. ${ }^{18}$ Destaca, por citar solo un ejemplo, el legajo titulado Cuenta y memoria de los gastos ... en la Escuadra de Mallorca para el Servicio de Su Majestad ... governandola el gobernador y capitán Pedro Flexas... ${ }^{19}$ Como se ve, un título muy parecido al anteriormente comentado, aunque en este caso las anotaciones se consignan de una forma mucho más ordenada, tanto caligráficamente como por lo que respecta a los sumatorios sobre precios, gastos o beneficios. Se relacionan las capturas realizadas por las distintas embarcaciones que formaban la Escuadra durante la segunda expedición (1677), se especifica el lugar concreto donde se hicieron, los bienes que se apresaron, el valor en venta de los mismos y, finalmente, se presenta un resumen de los beneficios de la expedición. En total, 170.846 libras, 1 sueldo y 9 dineros procedentes del valor de las ventas de las mercancías, que una vez descontados los gastos realizados por distintos conceptos en el transcurso del viaje (112.945 libras y 4 sueldos) suponen un beneficio neto de 57.905 libras, 1 sueldo y 9 dineros a repartir entre los distintos socios en función de las cantidades invertidas por cada uno. Se trata, desde el punto de vista económico, de un documento de gran valor. Si bien solo muestra un año concreto de actividad y no permite extraer, en consecuencia, una visión general de la intervención de los corsarios mallorquines en las dos expediciones de la campaña de Mesina, pues como hemos apuntado se refiere únicamente a la segunda. ${ }^{20}$

Con todo, lo que interesa subrayar es que documentalmente el hecho de que el corso fuera una actividad en la que económicamente participaba la Corona y que legalmente tenía que autorizarse, acreditaba a las instituciones reales a fiscalizar los resultados, pudiendo obligar periódicamente a los particulares a entregar cierta documentación que sí estaba sujeta a revisión. En el caso de los corsarios mallorquines y de la Escuadra de Mallorca en particular, dicha documentación se ha conservado (fundamentalmente en forma de memoriales) en el Archivo de la Corona de Aragón y su exploración, junto con la sistematización de las actas notariales que contienen las inversiones de los armadores y se conservan en otro archivo público (el Archivo del Reino de Mallorca), nos ha permitido obtener una visión de conjunto sobre el funcionamiento de dicha empresa. Los puntos principales sobre los que profundizamos son los siguientes:

17. Véase la gradación de los mismos en el cuadro 8 del Apéndice.

18. En este caso, se encuentran en el Archivo del Marqués de La Torre y, dado que ha sido objeto de un vaciado temático, resulta fácil acceder a la documentación sobre corso.

19. ARM. Archivo del Marqués de La Torre, legajo $59 \mathrm{M}$, pliego 2/38.

20. Lo mismo sucede, por citar un último ejemplo, si intentamos reconstruir su actividad a partir de los papeles del capitán Juan Ballester (Cirera, 1942). 
- Los costes del armamento y la extracción socioprofesional de los inversores.

— Las condiciones o reglas del juego a seguir por los particulares y la Corona.

- El desglose de gastos e ingresos de la segunda expedición (1677-1678).

- La forma de proceder en el reparto de los beneficios.

- La desmembración de la empresa y el riesgo de las asimetrías informativas para los negocios corsarios.

\section{Armamento e inversores de la Escuadra}

Las cantidades invertidas por los socios se escrituraban, como era frecuente en las empresas comerciales y marítimas en general, en un documento público rubricado por un notario que solía participar, a la vez, en los negocios de la empresa. Una mención especial merecen, para el ejemplo que nos ocupa, las sucesivas actas conservadas entre los protocolos del notario Juan Servera. ${ }^{21}$ Su sistematización permite reconstruir el coste de los armamentos con la indicación expresa de sus partícipes y, en nuestro caso, con anterioridad a la firma del primer acuerdo entre los armadores y el representante real, firmado el 16 de diciembre de 1674, disponemos de dos relaciones fechadas a 24 y 25 de febrero del mismo año en las que se consignan las aportaciones individuales para el armamento de dos embarcaciones. Se trata, por un lado, de la capitana Santa Cruz, a cuyo mando figuraba el capitán Pedro Flexes, y, por otra parte, de Nuestra Señora del Rosario, capitaneada por Jaime Ballester. En ambos casos se consignan, además de las cantidades aportadas, el estatus de cada inversor, una información que resulta de gran utilidad para conocer la extracción socioprofesional de los armadores. En otras actas posteriores, escrituradas entre 1674 y 1677, se registran nuevas inversiones que suponen el armamento de doce naves y un total invertido de 133.763 libras, 10 sueldos y 10 dineros. ${ }^{22}$ El cuadro 1 recoge la relación individual extraída de dichos protocolos y las inversiones realizadas en distintas fechas para un total de doce naves.

21. ARM. Protocolos Notariales de Juan Servera (S-994, 995, 996, 997, 998).

22. En la documentación consultada, los valores monetarios se expresan, generalmente, en la moneda de cuenta propia de Mallorca, es decir, en libras, sueldos y dineros: 1 libra $=20$ sueldos y 1 sueldo $=12$ dineros. No obstante, en los documentos generados por los representantes reales, las unidades monetarias se expresan en moneda castellana: pesos, doblones y reales de a ocho o reales de plata. Por ello, siempre que ha sido posible, hemos procurado dar las equivalencias en moneda de Mallorca. Teniendo en cuenta que un peso equivale a un real de a ocho o real de plata y que su equivalencia en moneda mallorquina son 272 dineros (1,13 libras). 
CUADRO 1 - Armamentos de la Escuadra de Mallorca y cantidades invertidas en cada barco (1674-1677)

\begin{tabular}{lccc}
\hline \multicolumn{1}{c}{ Nombre de la embarcación y fecha } & \multicolumn{3}{c}{ Moneda de Mallorca } \\
\hline & Libras & Sueldos & Dineros \\
\hline 1. Capitana Santa Cruz (24/2/1674) & 10.752 & 16 & 2 \\
\hline 2. Nuestra Señora del Rosario (25/2/1674) & 8.124 & 10 & 4 \\
\hline $\begin{array}{l}\text { 3. Santa Teresa (19/1/1675) } \\
\text { 4. Capitana Santa Cruz y almiranta San } \\
\text { José (7/2/1676) }\end{array}$ & 9.700 & & 9 \\
\hline $\begin{array}{l}\text { 5. La Concepción (22/5/1677) } \\
\text { 6. Capitana Santa Cruz y almiranta San } \\
\text { José (22/5/1677) }\end{array}$ & 15.921 & 19 & 4 \\
\hline $\begin{array}{l}\text { 7. Capitana Santa Cruz, almiranta San José } \\
\text { y patache San Andrés (26/5/1677) }\end{array}$ & 34.494 & & \\
\hline $\begin{array}{l}\text { 8. Patache Santa Teresa (8/7/1677) } \\
\text { Total }\end{array}$ & 9.300 & 12 & \\
\hline
\end{tabular}

Fuente: Elaboración propia a partir de las actas notariales (ARM. S-994 a 998) y los datos de Cirera (1942).

En los doce armamentos reseñados participan, aunque de forma muy desigual, un total de 47 personas (incluidas algunas compañías). Sin embargo, si atendemos a la cuantía de sus inversiones, sobresalen las realizadas por un grupo muy reducido de mercaderes y nobles. En primer lugar, el mercader Juan Ballester (el máximo inversor en solitario con un poco más de 25.000 libras), seguido del también mercader Juan Bautista Suñer, con una cantidad muy similar (24.006 libras), y los mercaderes de adscripción judeo-conversa Gabriel, Agustín Antonio y Alex Cortés, con una inversión conjunta de alrededor de 16.500 libras. Destacan, a continuación, las partidas invertidas por los dos miembros de la alta nobleza mallorquina que desde tiempo atrás venían apostando por el corso: ${ }^{23}$ Ramón Despuig, conde de Montenegro y de Montoro, con 18.809 libras, y Juan Miguel Sureda, padre del futuro primer marqués de Vivot, con 13.438 libras. En conjunto, las cantidades aportadas por estos cinco inversores representan alrededor del 73\% de la inversión total, lo que significa, en la práctica, que los beneficios de la empresa se repar-

23. De estos nos consta que, paralelamente, tenían inversiones en otros negocios y, en muchos casos, aparecían asociados igualmente con mercaderes pertenecientes al colectivo judeo-converso. Un colectivo que, aunque socialmente estaba discriminado, no tenía prohibido el mercadeo. En la práctica, hasta el final del Antiguo Régimen, controló el comercio exterior e interior de la isla. Véanse Montaner (1978, 1979-80, 1984 y 1990), López Nadal (1987), Bibiloni (1995), Pons (1996) y López y Manera (2000) sobre su papel económico durante la Edad Moderna. Sobre su especialización profesional hasta épocas recientes: Aguiló (2016) y Aguiló y Morey (2016). 
CUADRO 2 - Distribución por profesión y/o adscripción social de los inversores de la Escuadra de Mallorca

\begin{tabular}{lcc}
\hline \multicolumn{1}{c}{ Estatus/Profesión } & Libras & $\%$ \\
\hline Mercaderes & 73.233 & $54,75 \%$ \\
\hline Nobles & 37.680 & $28,17 \%$ \\
\hline Capitanes & 15.205 & $11,37 \%$ \\
\hline Artesanos & 5.050 & $3,77 \%$ \\
\hline Representantes reales & 2.595 & $1,94 \%$ \\
\hline Total & $\mathbf{1 3 3 . 7 6 3}$ & $\mathbf{1 0 0 , 0 0 \%}$ \\
\hline
\end{tabular}

Fuente: Elaboración propia a partir de las cantidades consignadas en el cuadro 8 del Apéndice.

tirían entre un grupo muy reducido de personas. Dicho esto, interesa también fijarse, independientemente del montante de las cantidades arriesgadas, en la adscripción socioprofesional del conjunto de los armadores sintetizada en el cuadro 2.

Observamos, en primer lugar, como solía ser habitual en este tipo de empresas, el predominio de individuos pertenecientes al estamento mercantil. En conjunto, invierten un total de 73.223 libras, lo que supone más de la mitad del cómputo total, concretamente casi el 55\%. Sobresalen, a continuación, las inversiones de los miembros pertenecientes al brazo noble con un montante de 37.680 libras (el 28,17\%) y, en tercer lugar, las de los capitanes de los distintos navíos que representan un poco más del 11\%. En muchos casos estos últimos pertenecían también al estamento mercantil; sin embargo hemos optado por incluirlos en un epígrafe independiente porque, por su condición de capitanes, tenían mayores opciones de beneficio, pues además de la parte proporcional correspondiente a la inversión realizada tenían derecho a percibir el $10 \%$ sobre el beneficio bruto de las capturas. Destacan, en este grupo, las cantidades aportadas por el capitán Pedro Flexes, en total casi 8.000 libras, que en términos porcentuales se traducen en prácticamente un $6 \%$ sobre el total y lo colocan en la sexta posición entre los inversores de la Escuadra.$^{24}$ Sobresalen, a continuación, las 2.240 libras arriesgadas por el capitán Jaime Canals, que aunque representan solo el 1,68\% sobre el total, le otorgan el segundo puesto dentro de este grupo. ${ }^{25} \mathrm{El}$ resto de los capitanes participan con cantidades que oscilan entre las 1.000 y las 1.600 libras, constituyendo la única excepción remarcable el caso de Antonio Dameto, quien por linaje pertenecía a la nobleza y, quizás por ello, fue nombrado gobernador de la Escuadra. No

24. Sobre el reconocimiento social del que llegó a gozar: Planas (2011).

25. Sobre el patrimonio de este capitán de origen modesto: López Nadal (2009). 
obstante, su inversión en términos económicos fue más bien simbólica: participó en solo dos armamentos con un total de 100 libras.

Otro colectivo que llama la atención es el formado por un grupo de artesanos (herreros, carpinteros, boteros y varios farmacéuticos o boticarios) que, en conjunto, aportan una cifra que puede considerarse testimonial (5.050 libras, equivalentes al $3,77 \%$ sobre el total) y cuya participación entendemos que está relacionada con el hecho de que debieron de aportar material o trabajo en el transcurso de los preparativos y, probablemente, en lugar de recibir una retribución en dinero por las mercancías aportadas o los trabajos realizados, fueron compensados con una participación proporcional en el negocio. Por último, hemos agrupado las inversiones realizadas por los representantes institucionales, que, además de rubricar y/o elaborar los documentos para que la empresa pudiera salir adelante, figuran también como inversores. Se trata, concretamente, del capitán general y virrey de Mallorca (Francisco Cebrián, conde de Fuenclara, de origen aragonés y que ocupó el cargo entre junio de 1671 y mayo de 1675), el notario Juan Servera, encargado de rubricar las actas, y el escribano Cristóbal Seguí. En conjunto, aportan la cantidad de 2.595 libras (el 1,94\% sobre el total). Sin embargo, destaca, sobre todo, la cifra aportada por el capitán general (casi 2.500 libras), pues las cantidades comprometidas por el notario y el escribano son más bien simbólicas: 76 y 25 libras respectivamente. En definitiva, su presencia pone de manifiesto la ya citada simbiosis entre el interés general y los beneficios de los particulares, a la vez que la implicación personal de los representantes institucionales en la institución corsaria. Al fin y al cabo, es el virrey quien otorga la patente para acudir al corso y emite sentencia sobre si las presas se han realizado acorde a la ley, mientras que el notario rubrica, con su firma, la legitimación de la depredación. Lo que significa, en suma, que su participación como inversores puede dar lugar a un dilema de naturaleza jurídica, en buena medida porque ambos personajes eran juez y parte de un mismo proceso.

\section{Los contratos entre los armadores y la corona}

Las reglas del juego y el modus operandi de la empresa se fija en los acuerdos que antes del inicio de cada campaña firman los armadores con el delegado real. No conocemos precedentes sobre los contratos establecidos entre la marina real y las escuadras privadas de sus súbditos; de hecho, gracias a disponer de los firmados en 1674 y 1677 por el representante real y los responsables de la Escuadra de Mallorca, tenemos noticia de esta práctica. Se antoja difícil, por tanto, analizarlos en comparación con otros similares. Y es que, hasta el momento, no existen monografías sobre el corso ejercitado por los distintos territorios marítimos que abarcaba la monarquía católica, al me- 
nos en el Mediterráneo. Para el caso que nos ocupa, dos son los acuerdos firmados con Pedro Vázquez Torrero, caballero de la Orden de Santiago, veedor y proveedor general del Ejército de Cataluña, sobre la participación de la Escuadra en el sitio de Mesina. Se estipulan, respectivamente, el 16 de diciembre de 1674 (primera expedición) ${ }^{26}$ y el 19 de enero de 1677 (segunda expedición), ${ }^{27}$ y presentan diferencias y similitudes sobre las que interesa detenernos. Ambos contratos fueron analizados, en su conjunto, en un trabajo previo ${ }^{28}$ en el que ya se subrayó que presentaban una diferencia sustancial. Mientras que el primero se ejecutó siguiendo rigurosamente sus pautas, el segundo parece que quedó en mero proyecto porque una sentencia real desestimó, a última hora, su materialización. Tras la íntegra transcripción del mismo en uno de los libros de contabilidad sistematizados, se puede leer la siguiente aclaración: «Despues sucedió que entre en el Gobierno de la Monarquia [...] Su Alteza $[\ldots]$ no parecio admitir este servicio» ${ }^{29}$

Entendemos que la marcha atrás pudo deberse a la seguridad por parte de la Corona de que, con o sin contrato, los corsarios mallorquines iban a actuar igualmente beneficiándose de las interferencias del comercio francés. No solo del que iba a abastecer a la ciudad siciliana, sino también - y de hecho es lo más importante-, de la interrupción de la ruta levantina con destino al puerto marsellés del Lacydon, como así sucedió. En cualquier caso, e independientemente de que los acuerdos mencionados se siguiesen o no al pie de la letra, resultan de gran interés, para aproximarnos al funcionamiento de este tipo de empresas, conocer los costes del armamento, las cantidades aportadas por cada uno de los socios, las partidas pagadas por distintos conceptos, el nombre y las características de las embarcaciones que componían la escuadra, así como las capturas realizadas, los principales productos transportados por las naves interceptadas, los beneficios conseguidos con la venta de los mismos y la forma como estos posteriormente se reparten, si bien las anota-

26. El contrato original se conserva entre los protocolos notariales de Juan Servera (ARM. S-944, ff. 209-15v). Fue transcrito por Cirera (1942), pp. 358-362.

27. Este segundo contrato figura, igualmente, entre los protocolos de Juan Servera (ARM. S-977, ff. 33.44v), véase también López Nadal (1995), pp. 158-162.

28. López Nadal (1991).

29. Como se desprende del contenido de la siguiente carta: «Pedro Vazquez Torrero mi Vehedor General del exerssito de Cataluña con vuestra carta de 14 de pasado se ha recibido el papel de condisiones para la formación de la Esquadra de Vajeles que ofrecvio el Conde de Montenegro y participes para servir por tiempo de seis meses en las costas de Sicilia y habiéndose considerado que por el porte y la calidad dellos no son capaces de oponerse a los del enemigo por ser mucha fuerza se ha tenido por conveniente no admitirla y assi lo podréis dar a entender a los interesados que me ha sido de mucho agrado el celo y prompitud con que se disponían a hacerme este servicio y porque añadis que para facilitarle mas se havia dispuesto con e Virrey de Mallorca Marques de la Casta suspenderia el corso de los naturales della mientras se trataba del armamento desta esquadra porque no faltaren marineros para ella le prebendeis excuse esta prohivision. Buen Retiro 6 de Febrero de 1677. YOEL REY = por mandato del Rey Nro Sr Geronimo De Eguia». 
ciones sobre ingresos y gastos se realizan sin ningún tipo de metodología contable y carecen de la estructura suficiente para obtener un balance final, razón por la cual se pueden extraer solo algunos datos parciales.

Desde el punto de vista formal (presentación, expresiones protocolarias, número de cláusulas, etc.) ambos contratos son prácticamente idénticos. Los dos se firman, de entrada, para un mismo período de tiempo (seis meses) y, dado que la finalidad es la misma, «impedir con todas sus fuerzas, cuidado y diligencia que el enemigo no introduzca en ella gente, víveres y otras previsiones», resulta comprensible que los aspectos que se regulan sean prácticamente los mismos. Los principales puntos sobre los que se pacta son: la fecha de partida y el itinerario a seguir, el porte de los barcos y la composición de la tripulación, las cantidades a pagar por la Corona y la forma como estas se han de percibir. La salida se prevé, en ambos casos, desde Mallorca: la fecha de la primera expedición se estipula para el mes de diciembre de 1674, fijándose el punto de reunión con la Escuadra Real en el puerto de Melazzo, mientras que la partida de la segunda, esta vez hacia Palermo, se estipula para el mes de marzo de 1677.

En ambos documentos se ofrecen detalles sobre la envergadura de las expediciones, si bien la potencia artillera (piezas de hierro y de bronce) de la segunda expedición fue superior a la de la primera (cuadro 3). Esta superioridad se constata, igualmente, en relación con la tripulación: 650 hombres en la primera y 900 en la segunda, incluidos en ambas los capitanes y oficiales. Así mismo, dadas las dificultades que había en la isla para contratar a gente de mar, los armadores solicitan poderla traer de otros puertos italianos. ${ }^{30}$ Del mismo modo, piden que durante el tiempo que dure el servicio se suspenda el corso y la salida de saetías y otras embarcaciones menores. La siguiente cita, tomada del segundo contrato, pone de manifiesto dichos temores: «Suplicamos a Su Magestad que durante el apresto de de dixos vaxeles y por el tiempo de seis meses de este servicio mande suspender en esta Ciudad el corso...». ${ }^{31}$ Sobre el control de la «gente del mar» se pacta que corresponderá a los oficiales «de sueldo», mientras que el veedor general o la persona que él designase pasará revista a las fragatas. En el segundo acuerdo se reconoce, además, la conveniencia de otorgar el título de gobernador general de la Escuadra a Pere Flexes, capitán de fragata en ambas expediciones y destacado inversor. Así mismo, y también en ambos contratos, se estipula expresamente que, una vez cumplidos los seis meses de servicio, dicho capitán tendrá libertad para

30. La solicitud de los armadores dice textualmente: «... por cuanto se reconoce falto de gente de mar en este Reyno respecto de las saetías que de presente se hallan navegando en corso y de parte de los armadores y dueños de la Esquadra se han dado ordenes y remitido dinero effectivo a Genova y Liorna para que se levante y trayga en la fragata La Concepción [...] quatrocientas plaças o lo más que fuera posible» (López Nadal, 195, p. 154).

31. López Nadal (1995), p. 154. 
volver a Mallorca o tomar el rumbo que desee siempre y cuando se lo comunique al general de la Armada Real.

Como ilustran los cuadros 3 y 4, en el caso de la segunda expedición se trata de una flotilla de considerables dimensiones, ya por su potencia y capacidad de desplace, ya por lo que respecta al casi millar de hombres transportados: casi el doble de los que habría ocupado la primera escuadra. De ahí que la cantidad que en cada caso se estipula que van a percibir los armadores por el servicio difiera de forma sustancial: 55.000 pesos para el primer viaje y 77.500 para el segundo, equivalentes, respectivamente, a 62.150 y 87.575

CUADRO 3 - Piezas de artillería de cada expedición

\begin{tabular}{|c|c|c|}
\hline \multicolumn{3}{|c|}{ 1) Primera escuadra $(16 / 12 / 1674)$ compuesta por cuatro fragatas } \\
\hline Embarcación & Piezas de hierro & Piezas de bronce \\
\hline Capitana Santa Cruz & 44 & 10 \\
\hline Almiranta La Concepción & 24 & 20 \\
\hline Santa Teresa & 20 & 16 \\
\hline Santiago & 20 & 10 \\
\hline \multicolumn{3}{|c|}{ 2) Segunda escuadra (17/1/1677) compuesta por cuatro fragatas y un patache } \\
\hline Embarcación & Piezas de hierro & Piezas de bronce \\
\hline Capitana Santa Cruz & 44 & 12 \\
\hline Almiranta La Concepción & 60 & 20 \\
\hline San Antonio & 36 & 12 \\
\hline San José & 20 & 24 \\
\hline San Andrés & 17 & 12 \\
\hline
\end{tabular}

Fuente: Elaboración propia a partir de los protocolos indicados (ARM, S- 994 y S-997).

CUADRO 4 - Capacidad y tripulación de la segunda escuadra (17-01-1677)

\begin{tabular}{lcc}
\hline \multicolumn{1}{c}{ Embarcación } & Porte (toneladas) & Plazas \\
\hline Capitana Santa Cruz & 350 & 200 \\
\hline Almiranta La Concepción & $500 / 600$ & 290 \\
\hline San Antonio & 280 & 240 \\
\hline San José & 200 & 120 \\
\hline San Andrés & 150 & 110 \\
\hline Total & $\mathbf{1 . 4 8 0 / 1 . 5 8 0}$ & $\mathbf{9 6 0}$ \\
\hline
\end{tabular}

Fuente: Elaboración propia (ARM, S- 997 ff .3v-7v). 
libras mallorquinas. ${ }^{32}$ Difiere, así mismo, la forma y los plazos en los que el representante real se compromete a hacer efectivas dichas cantidades. En el primer acuerdo se pacta que, en cuanto las naves estén dispuestas para zarpar, los armadores recibirán, en la ciudad de Mallorca, 10.000 pesos en moneda corriente (equivalentes a 11.300 libras), debiéndose pagar los restantes en la ciudad de Barcelona en seis plazos consecutivos. Dichas cantidades se incrementan en el segundo contrato, fijándose la cuantía inicial en 30.000 pesos (33.900 libras) pagaderos al contado en la ciudad de Mallorca y en el plazo de los cincuenta días posteriores a la firma del acuerdo. Respecto al dinero restante, deberá pagarse en la ciudad de Barcelona en seis plazos consecutivos, debiéndose empezar a satisfacer a los dos meses de haber zarpado las embarcaciones. En el segundo contrato se añaden, además, dos cláusulas en el supuesto de que la ciudad de Mesina sea reducida antes de lo previsto. Se pacta, por un lado, que si esto ocurre antes de la llegada de las embarcaciones mallorquinas, no se retornarán los 30.000 pesos recibidos, pudiendo la flota mallorquina tomar viaje hacia las costas de Berbería o cualquier otro territorio infiel. Se estipula, por otro, que si la ciudad es conquistada antes de los seis meses y el servicio finaliza antes de lo previsto, los inversores percibirán solo la parte proporcional. ${ }^{33}$

$\mathrm{Al}$ referido coste y anticipo se añaden otras dos condiciones. La primera afecta a la determinación de no permitir nuevos armamentos en corso a fin de no dispersar a una marinería ya algo escasa, mientras que la segunda, a la lógica exigencia de condonación del quinto real: el impuesto que se cobraba el soberano de las presas que sus súbditos hacían «en mar y tierra». ${ }^{34}$ Se estipula, además, que si en el transcurso del servicio, «lo que Dios no quiera», se perdiese alguna embarcación, ni la Corona tendrá obligación de pagarla, ni los armadores deberán deducir nada de los 77.500 pesos pactados. ${ }^{35}$ Ambos contratos finalizan con el compromiso de las partes implicadas de cumplir todos los pactos y con la promesa de los inversores de responder con sus bienes presentes y futuros. Sin embargo, por un anexo añadido el 6 de febrero de 1677 al contrato original, sabemos que finalmente Pedro Vázquez no admite la propuesta inicial de los armadores. Pese a manifestar su agrado por el celo y prontitud con que se disponían a ofrecer este servicio, considera que el porte y la calidad de las embarcaciones ofrecidas es insuficiente para oponerse al enemigo.

32. En el primer acuerdo los armadores añaden que, si al llegar a las costas de Mesina, la ciudad ha sido recuperada, se les deberán abonar 10.000 pesos (ARM, S-997, ff. 34-44v).

33. Entendemos que este tipo de aclaraciones responden a posibles imprevistos surgidos durante la primera expedición.

34. López Nadal (1988).

35. En el segundo contrato se estipula, además, que si por alguna circunstancia adversa las embarcaciones no pudieran salir con la Escuadra Real, lo harán cuando lleguen, no siendo tampoco necesario que salgan las cinco embarcaciones juntas. 
Es probable que la estipulación de un coste tan elevado actuara como factor determinante para que la Corona decidiera, finalmente, rescindir el servicio previamente acordado. Sin embargo, no hay que descartar que el asesor real lo desestimara, precisamente, para ahorrar gastos a las arcas reales. Pues hubiera resultado difícil de entender que, después de las inversiones realizadas, con contrato o sin él, los corsarios isleños no se arriesgaran a apoyar la causa real ya que, de lo contrario, sus pérdidas hubieran sido cuantiosas. Y, desde luego, era mucho más conveniente para las arcas reales que los corsarios actuaran por cuenta propia, dado que de este modo la Corona obtendría un mismo beneficio sin tener que pagar por ello. Para los armadores este cambio repercutió, sin duda, en sus beneficios finales, aunque al menos parcialmente recibieron parte del dinero comprometido. Nos consta, así mismo, que sus actuaciones en aguas cercanas a Sicilia fueron de gran ayuda a la causa del rey católico y, por lo que se desprende del resumen económico de la segunda expedición, los beneficios fueron en principio considerables, si bien a medio plazo no resultó todo lo lucrativa que se esperaba.

\section{Cuentas del segundo viaje (1677-1678)}

Los gastos y beneficios de la segunda expedición pueden reconstruirse a través de un memorial conservado en el Consejo de Aragón y de otros estados de cuentas hallados en los archivos particulares de algunos armadores. ${ }^{36}$ El siguiente cuadro contiene un resumen organizado por grandes partidas y subdividido por epígrafes. En el capítulo de gastos destacan, en primer lugar, los relativos al armamento de las cinco embarcaciones. Porcentualmente representan más de la mitad del coste total (el 56,79\%), incluidos los gastos derivados de la puesta a punto de la embarcación capturada a los franceses bajo el nombre de La Nueva Jerusalén y posteriormente rearmada para formar parte de la Escuadra de Mallorca. Destacan, a continuación, los gastos derivados de los viajes, de duración comprendida entre los nueve y los doce meses, de las cinco naves: en total ascienden a 17.800 libras (el 15,76\%). Se trata, sobre todo, de dispendios relacionados con la carena de las naves y el aprovisionamiento de la marinería, ${ }^{37}$ ya que los salarios se consignan en una partida independiente y su coste total se calcula en 6.000 libras (el 5,32\%). Un lugar destacado ocupan, igualmente, los gastos derivados del proceder de las

36. Se trata de un documento conservado en el Consejo de Aragón (ACA, Legajo n. ${ }^{\circ}$ 999) y de los registros ya citados localizados en los archivos del conde de Montenegro y del marqués de Vivot.

37. Entre los documentos que forman parte del Llibre del Gasto del Armament destaca una relación de los gastos derivados de la comida de la gente que trabajaba en las atarazanas de Portopí (López Nadal, 1995). 
naves en los distintos puertos de escala. En total 10.000 libras (el 8,85\%) por los derechos de cuarentena, portes, pesador, etc. Como se ve, una cantidad idéntica a la que se calcula por los costes de aduanas. ${ }^{38}$ En este apartado se consigna, así mismo, la pérdida (seguramente por captura) del patache San Andrés que, aunque solo representa el $4,43 \%$ sobre el total, ilustra a la perfección el elevado riesgo que corrían las empresas marítimas en general y las corsarias en particular.

CUADRO 5 - Desglose de los gastos e ingresos del segundo viaje en corso de la Escuadra de Mallorca (1677-1678)

\begin{tabular}{lccc}
\hline A. GASTOS & \multicolumn{3}{c}{ Cantidad en libras y porcentaje } \\
\hline & $\mathbf{6 4 . 1 4 1}$ & $\%$ & $\%$ \\
\hline 1. Total armamentos & 34.741 & $54,16 \%$ & \\
\hline $\begin{array}{l}\text { Capitana Santa Cruz, gobierno San } \\
\text { José y patache San Andrés }\end{array}$ & 15.800 & $24,63 \%$ & \\
\hline Almiranta La Concepción & 9.600 & $14,97 \%$ & \\
\hline Patache Santa Teresa & 4.000 & $6,24 \%$ & \\
\hline La Nueva Europa & $\mathbf{1 7 . 8 0 0}$ & & $\mathbf{1 5 , 7 6 \%}$ \\
\hline 2. Total gastos viaje & 4.600 & $25,84 \%$ & \\
\hline Capitana Santa Cruz (9 meses) & 5.000 & $28,09 \%$ & \\
\hline Almiranta La Concepción (9 meses) & 3.200 & $17,98 \%$ & \\
\hline Gobierno San José (1 año) & 2.800 & $15,73 \%$ & \\
\hline Patache San Andrés (1 año) & 2.200 & $12,36 \%$ & \\
\hline $\begin{array}{l}\text { Patache Santa Teresa (9 meses) } \\
\text { 3. Salarios de la «gente del mar» } \\
\text { (cinco navíos) }\end{array}$ & $\mathbf{6 . 0 0 0}$ & & $\mathbf{5 , 3 1 \%}$ \\
\hline $\begin{array}{l}\text { 4. Gastos de cuarentena, pesador y } \\
\text { descarga }\end{array}$ & $\mathbf{1 0 . 0 0 0}$ & & $\mathbf{8 , 8 5 \%}$ \\
\hline $\begin{array}{l}\text { 5. Derechos de aduanas de todas } \\
\text { las presas }\end{array}$ & $\mathbf{1 0 . 0 0 0}$ & & $\mathbf{8 , 8 5 \%}$ \\
\hline $\begin{array}{l}\text { 6. Pérdida patache San Andrés } \\
\text { Total gastos }\end{array}$ & $\mathbf{5 . 0 0 0}$ & & \\
\hline
\end{tabular}

(Continúa en la página siguiente)

38. En los contratos entre la Corona y los armadores nada se concreta respecto a la obligatoriedad de tributar por las capturas. Y, en este sentido, la partida llama la atención debido a que este tipo de armadas solían estar exentas de la mencionada obligatoriedad. Sin embargo, en el documento analizado queda claro que los derechos de aduanas corresponden a pagos sobre las presas y no por la compra de bastimentos. 


\begin{tabular}{|c|c|c|}
\hline \multirow[t]{2}{*}{ B. INGRESOS } & \multicolumn{2}{|c|}{ Cantidad en libras y porcentaje } \\
\hline & Libras & $\%$ \\
\hline Un navío hundido con siete turcos & 452 & $0,27 \%$ \\
\hline El navío francés La Nueva Jerusalén & 119.945 & $70,33 \%$ \\
\hline Una balandra mesinesa & 560 & $0,33 \%$ \\
\hline Un carbo de «moros» & 576 & $0,34 \%$ \\
\hline Una saetía francesa & 3.900 & $2,29 \%$ \\
\hline Una polacra francesa & 906 & $0,53 \%$ \\
\hline Una saetía francesa perdida en Menorca & - & $0,00 \%$ \\
\hline El patache francés San Jaime & 18.700 & $10,96 \%$ \\
\hline Otra saetía francesa & 1.700 & $1,00 \%$ \\
\hline La saetía francesa Santa Teresa & 1.474 & $0,86 \%$ \\
\hline Por la venta de unos turcos (695 pesos) & 785 & $0,46 \%$ \\
\hline Una polacra cuyo origen no se precisa & 793 & $0,46 \%$ \\
\hline Un navío con 85 turcos & 14.167 & $8,31 \%$ \\
\hline El navío La Nueva Europa una vez rearmado & 6.600 & $3,87 \%$ \\
\hline Total ingresos & 170.558 & $100 \%$ \\
\hline
\end{tabular}

Fuente: Elaboración propia (ARM. Archivo del Marqués de La Torre, legajo 59 M, pliego 2/38).

En el apartado de ingresos se consignan las presas realizadas durante la expedición. De las catorce capturas - en la práctica una menos, dada la pérdida de una saetía en Menorca - cinco fueron realizadas por la almiranta $\mathrm{La}$ Concepción, cuatro por la capitana Santa Cruz y otras cuatro por el gobierno San José; una de ellas en compañía del patache San Andrés, al que se le atribuye también una segunda captura. Como muestra el cuadro 5, la relación de presas comienza con la referencia a siete turcos procedentes de un navío capturado por la almiranta La Concepción en las costas de Berbería. En un epígrafe posterior se consigna la captura de un navío con 85 «turcos» realizada por la capitana Santa Cruz en las costas de Sicilia, los cuales fueron vendidos en Malta «a cien pesos cada uno» (113 libras mallorquinas). No obstante, la captura más importante de todas las realizadas por los corsarios isleños es, sin duda, la del navío La Nueva Jerusalén. ${ }^{39}$ Su valor se calcula en 119.945 libras 7 sueldos y 1 dinero -incluidas las 3.000 libras en las que se estimó el buque - y supera, en consecuencia, el monte total de la segunda expedición. La importancia de este apresamiento reside en su ingente cargamento, com-

39. Esta nave procedía de Esmirna y se dirigía hacia Marsella (López Nadal, 1986), pp. 67-68. 
puesto por tejidos orientales (seda, indianas, algodón, pelo de cabra y algodón en rama), cera, alfombras, camellote, cordobanes, vaquetas, cueros de vaca, etc. Entre las restantes presas realizadas a los franceses, destacan el patache San Jaime, La Nueva Europa, capturada en el puerto de Alexandreta, una saetía con provisiones para Mesina, otra saetía apresada en el «Archipiélago» - léase en el Mediterráneo oriental, zona en la que la capitana Santa Cruz capturaba la saetía Santa Teresa-, una polacra vacía por cuyo buque se pagaron 800 pesos (904 libras) y una saetía, cargada de vino y legumbres, que se perdió en Menorca. A estas se añaden una balandra mesinesa, realizada por la almiranta La Concepción en aguas sicilianas, y la apropiación de 695 pesos (alrededor de 785 libras) pertenecientes a unos turcos embarcados en un navío inglés retenido en las costas de Berbería.

\section{Reparto de beneficios}

Entre las distintas facetas que acreditan la esencia empresarial de la Escuadra de Mallorca cabe referirse al procedimiento respecto al reparto de las presas. Ya hemos visto la presencia y contribución individual de quienes participaban en comandita en sus armamentos, unos armamentos que prefiguran lo que va a ser, posteriormente, la distribución del botín. Antes de entrar en ello, conviene recordar, sin embargo, que siguiendo costumbres medievales, del beneficio neto del corso, es decir, después de amortizados sus costes de inversión, liquidado el quinto real, los derechos de pilotaje y los gastos de llegada a puerto, cuarentena, transportes, etc., se hacían tres partes: dos para los armadores — «per lo canó» y «per lo buc»—y una para la tripulación..$^{40}$ De este modo, los primeros recuperaban sus inversiones y disfrutaban de las dos terceras partes de las ganancias. De ello ha quedado también constancia en los protocolos notariales. A continuación transcribimos, a modo de ejemplo, un documento fechado a 24 de febrero de 1674, sobre el reparto de los beneficios de la capitana Santa Cruz:

...el procedit de totas las presas en primer lloch se pagara deu per cent per pilotatjes que se entregara a mi dit Capita Pere Flexes, despres las susditas Deu Mil Siscentas Sinquanta Vuit lliuras Sis sous y tres diners que coste lo present armament y axi mateix tots los drets y gastos que per benefici de ditas pressas se offeriran. Y de lo que restare net se han de fer tres parts, las quals se han de partir y partiran tres en ters al dit Capita, Oficials, Mariners y soldats del dit vaxell y los

40. Esta forma de proceder, conforme al denominado tercio vizcaíno, está documentada desde los orígenes de la unión de los reinos de Castilla y Aragón. Véanse, entre los trabajos ya clásicos, Fernández Duro (1972), vol. 5, pp. 8-9 y Azcárraga Bustamante (1950). 
dits dos tersos als dits señors. So es lo hun ters per lo armament y lo altre per lo buch, armas, veles y demes arreus... ${ }^{41}$

Se constata el gran partido obtenido por los capitanes, cuyo derecho de pilotaje les acarreaba, aparte de lo que les pudiera corresponder como armadores, el diez por ciento del beneficio bruto. Otros ejemplos permiten observar la desigual distribución de las ganancias entre los armadores, siempre en proporción a la inversión inicial. Sirva de ejemplo la forma de proceder recogida en el acta de 18 de julio de 1678 sobre el reparto de la nave La Nueva Jerusalén:

... Hazemos reparticion y repartimos el valor del buque, arreos, armas y xarxiames avalandolo en tres mil libras y por semejantes se ha dado crédito en el valor de todas las presas en la forma y modo siguiente. A saber es que del valor y primer coste del dicho navio La Nueba Hierusalem pertenece a mi dicho don Ramon Despuig Conde de Montenegro y de Montoro, una octava parte. Una diesiseysena parte, a mi dicho don Juan Miquel Sureda. Una octava parte, a mi dicho el capitan Jayme Canals .Una diesiseysena parte a nosotros dichos capitanes Pedro Flexas y Felix Sero. Una quarta parte por entrambos a mi dicho Juan Ballester mercader y el capitan Jayme Ballester mi hermano. Y a mi dicho Juan Antonio Scardo, en nombre del dicho Juan Bautista Suñer, la otra octava parte. Y en dicha conformidad se ha hecho el dicho repartimiento de dicho navio... ${ }^{42}$

Con todo, resulta muy difícil interpretar, sin temor al equívoco, si dicho reparto corresponde solo al buque o también a su carga, pues de afectar únicamente al navío, de estas palabras se colige una distribución «por acciones» entre los citados armadores y capitanes. Mientras que de significar el monte total de la presa - alrededor de 120.000 libras - cabría plantearse si a tal fecha se habría ya procedido a la venta de las mercancías y a la liquidación de las inversiones previas. De ser así, resulta extraño no encontrar todos los nombres de quienes habían armado la fragata La Concepción (su captora), mientras que sí figuran los de quienes habían invertido en otras naves de la Escuadra. Estas observaciones pueden servir también en lo referente al reparto proporcional de dos nuevas presas realizadas en la última expedición anterior a la Paz de Nimega: el patache San Jaime, capturado por el navío San José, y La Nueva Europa, capturada por la almiranta La Concepción. Los siguientes cuadros resumen la distribución de los repartos. ${ }^{43}$

41. ARM. S-994, ff. 41-41.

42. ARM. S-998, ff. $262 \mathrm{v}-266$.

43. ARM. S-998, ff. $212 \mathrm{v}-213$. 
CUADRO 6 - Reparto de beneficios del patache San Jaime

\begin{tabular}{lcc}
\hline \multicolumn{1}{c}{ Armador } & Porcentaje & Valor (libras y sueldos) \\
\hline Capitán Bernardino Estarellas & $5 / 8$ & 1.063 libras 8 sueldos \\
\hline Don Joan Miquel Sureda & $1 / 8$ & 212 libras 4 sueldos \\
\hline Capitán Pedro Flexas & $1 / 8$ & 212 libras 4 sueldos \\
\hline Don Ramón Despuig & $1 / 8$ & 212 libras 4 sueldos \\
\hline Total a repartir & & $\mathbf{1 . 7 0 0 ~ l i b r a s ~}$ \\
\hline
\end{tabular}

Fuente: Elaboración propia (ARM. S-998, ff. 212v-213).

CUADRO 7 - Reparto de beneficios de La Nueva Europa

\begin{tabular}{lcc}
\hline \multicolumn{1}{c}{ Armador } & Porcentaje & Valor (libras y sueldos) \\
\hline Don Ramón Despuig & $1 / 6$ & 1.000 libras \\
\hline Capitán Josep Cordilla & $1 / 8$ & 750 libras \\
\hline Capitán Jaime Ballester & $1 / 8$ & 750 libras \\
\hline Capitán Juan Ballester & $7 / 12$ & 3.500 libras \\
\hline Total a repartir & & $\mathbf{6 . 0 0 0 ~ l i b r a s ~}$ \\
\hline
\end{tabular}

Fuente: Elaboración propia (ARM. S-998, ff. 322).

Otro aspecto crucial, aunque en la actualidad todavía insuficientemente estudiado, es el relativo a la tipología de las inversiones realizadas con los beneficios del corso. Si bien en un trabajo anterior se adelantaban dos destinos principales: la reinversión en la propia empresa y la adquisición de bienes inmuebles. ${ }^{44} \mathrm{El}$ primero se entiende por el enorme interés en sacar el máximo partido de una estrategia que se sabía perentoria y extremadamente arriesgada. De hecho, la coyuntura bélica que lo favorecía permitía la realización de un negocio que en tiempos de paz apenas podía ponerse en práctica y, de ahí, la urgencia de equipar con rapidez nuevas embarcaciones, muchas veces sus propias presas, para así poder proseguir con la empresa de la depredación marítima. Según se ha podido comprobar, los partícipes en el armamento corsario no difieren, en términos generales, del comercio marítimo en general. ${ }^{45}$ Es más, son prácticamente unos mismos nombres quienes, al tiempo que arriesgan en armamentos corsarios, invierten en negocios marítimos de todo tipo y en seguros. ${ }^{46}$ Mayor interés reviste la orientación del beneficio corsario hacia la inversión en bienes inmuebles, pues gracias a la exploración de los tes-

44. Pascual (1989), López Nadal (1993a, 2009) y Planas (2011).

45. López Nadal (1987), Manera (1993) y Bibiloni (1995).

46. López Nadal (1987), Pons (1996), López y Manera (2000) y Aguiló (2016). 
tamentos e inventarios de algunos mercaderes y capitanes corsarios nos consta que eran propietarios de inmuebles, tanto en la ciudad como en el campo. No obstante, esta línea de investigación, todavía en curso, supera los objetivos concretos de este artículo. ${ }^{47}$

\section{La desmembración de la Escuadra}

La firma, el 19 de agosto de 1678, de la Paz de Nimega puso oficialmente fin a la contienda entre franceses y españoles. Si bien, pocos días antes, el 22 de junio, el rey católico había remitido a su representante en Mallorca unas reales órdenes incentivando nuevos armamentos. Una propuesta que repetiría dos meses más tarde, con las paces ya establecidas, y que ayuda a entender las desavenencias que posteriormente se suscitaron. ${ }^{48}$ En un memorial del capitán y armador Juan Ballester, trasladado al rey por el Consejo de Aragón el día 2 de octubre de $1686,{ }^{49}$ se hace hincapié en que las paces no se hicieron públicas en Mallorca hasta el mes de marzo de 1680, por lo que justifica que durante año y medio los corsarios prosiguieran apresando mercantes franceses. Estas capturas fueron vendidas, tras ser declaradas como bien realizadas, en la propia isla y en otros lugares del Mediterráneo, y sus botines se repartieron entre los interesados siguiendo el procedimiento ya comentado. Sin embargo, el hecho de que las presas fueran posteriores a la Paz de Nimega, acabó desencadenando la desarticulación de la Escuadra. A principios del año 1679 los franceses empezaron a presionar para recuperar sus naves apelando al cambio de coyuntura imperante en el momento de producirse el apresamiento. Desde entonces y hasta 1684 se vivió un intenso proceso en el transcurso del cual los armadores isleños, seguramente por pura estrategia, trataron desesperadamente de retener sus capturas, mientras que los franceses presionaban con dureza para obtener la restitución de las mismas. Finalmente, la «legalidad» acabó imponiéndose y el rey católico, a través del Consejo Supremo de Guerra, ordenó a sus súbditos isleños la entrega de todas las embarcaciones involucradas.

Según consta en otro memorial redactado en 1680 por don Ramón Despuig y don Juan Miquel Sureda, las presas obligadas a devolver a los franceses fueron al menos seis. Se refieren, concretamente, a la retención de cuatro de sus bajeles en el puerto de Cagliari, y al «embarrancamiento» del navío Jerusalén en el puerto de Lisboa, tras el intento de ser apresado por los france-

47. En la actualidad estamos trabajando sobre la formación y composición del patrimonio del mercader Juan Ballester, armador y capitán de la Escuadra de Mallorca (Morey, 2016).

48. López Nadal (1998), p. 75.

49. ACA. Consejo de Aragón, legajo 999. 
ses. Así mismo, a la detención en Corfú, en abril de 1681, de La Virgen de Europa por las galeras venecianas. ${ }^{50} \mathrm{El}$ descalabro se vería completado tras la captura de la capitana Santa Cruz por parte de los berberiscos a principios de mayo de 1683 «a cien millas de Levante de Mallorca». ${ }^{51}$ Ante estos infortunios los armadores trataron, cuando menos, de cobrar lo que se les debía por haber armado cinco naves para asistir a las galeras reales en el sitio de Mesina. Sin embargo, el día 11 de noviembre de 1680 denunciaban que de los 77.500 pesos inicialmente estipulados habían recibido solo 42.200 reales de a ocho. ${ }^{52}$

El desprendimiento por venta de las naves que habían formado parte de la Escuadra era otra forma de mitigar las pérdidas, pero en la práctica implicaba la desarticulación de la empresa, lo que explica las reticencias iniciales del poder real. Las gestiones al respecto empezaron, de hecho, el 12 de mayo de 1680 con el traslado por parte del virrey Villar al Consejo de Aragón de la petición de los armadores de obtener licencia para vender a los franceses sus tres principales navíos porque «con toda instancia y ventaja de precios hace muchos días que solicitan comprarlos». ${ }^{53} \mathrm{El}$ virrey justifica su negativa por considerar poco adecuado pagar al enemigo entregándole sus mejores armas. Pese a ello, los armadores prosiguen en su intento y en breve comienzan las ventas. La primera nave de la que se desprenden es La Concepción. ${ }^{54}$ Otra nave implicada fue la Nueva Europa, capturada en 1677 a los franceses y empleada como buque en los apresamientos de la Santa Julia y Les Saintes Reliques. A 30 de noviembre de 1680 el conde de Montenegro y de Montoro y Juan Ballester delegaron la gestión de su venta «en cualquier parte del mundo» al capitán Jaime Ballester y al patrón Bartolomé Barceló. ${ }^{55}$ Sin embargo, la operación debió de frustrarse, ya que nos consta que posteriormente zarparía de Mallorca para buscar trigo en Levante, viaje que terminaría en la República de San Marco tras su detención en Corfú por los venecianos. Algo similar debió de ocurrir con la capitana Santa Cruz, pues el 17 de noviembre de 1682 sus dueños designaban como procurador al genovés Joseph Lladó para «poder venderla o enagenarla... con sus armas, jarcias y demás atrases». ${ }^{56}$

Por todo ello, en el citado informe de 1680 los armadores concluirán que el estado de la Escuadra de Mallorca era ruinoso. Habían tenido que entre-

50. Archives de France. Sección de la Merine. Serie B 4.9, documento 186.

51. Fajarnés (1898), p. 190 y López Nadal (1986), p. 397.

52. Tal y como se había convenido por la ampliación del servicio durante cuatro meses, según consta por acta notarial del 14 de julio de 1675 (López Nadal, 1998), p. 70

53. ACA. Consejo de Aragón, legajo 998.

54. ARM. S-1002 f. 152.

55. Su captura por los berberiscos frustró, no obstante, dicha permuta (ARM. S-1000, ff. 236-237v).

56. La transacción debía realizarse una vez que la capitana hubiera regresado del viaje de «fletamiento de trigos para provisión de este Reyno» (ARM. S-1002, ff. 152-153v). 
gar a los franceses el valor de sus presas y cuatro de sus embarcaciones habían quedado retenidas en Cagliari. De ahí que solicitaran con urgencia la restitución de las cantidades que todavía se les debían y propusieran que estas se obtuvieran de los bienes confiscados a los conversos. ${ }^{57}$ Desconocemos los resultados de la gestión, pero intuimos que pudo haber sido positiva, lo que se colige de un nuevo memorial elevado a principios de 1684. Entonces los armadores tratan de explicar la conveniencia de reemprender el corso y, al no poder disponer de tres navíos de la Armada Real, proponen construirlos. ${ }^{58}$ En esta ocasión hay constancia de que se obtuvo, al menos parcialmente, una respuesta favorable. A pesar de que en un real despacho de 24 de noviembre de 1684 se ponía de manifiesto la contracción de las actividades corsarias: «...hoy no queda otro corso que contra Turcos de que no se sacan las utilidades que contra otras naciones de comercio». ${ }^{59}$ De ahí que la coyuntura no se vislumbraba demasiado favorable para incrementar nuevos armamentos.

A principios de 1684, Francia y España reanudaron sus hostilidades, pero la Tregua de Ratisbona, sellada a 29 de junio del mismo año, significó nuevamente el cese de las actividades corsarias y poco después, en misiva real, se ordenaba al Consejo de Aragón que informase sobre las presas hechas con posterioridad al 15 de agosto. ${ }^{60}$ Apenas se concedía mes y medio para que los corsarios acataran la nueva situación, pero esta vez no hay constancia de controversias posteriores. ${ }^{61}$ Sin duda, lo ocurrido después de la Paz de Nimega debió de resultar, como mínimo, ejemplarizante. Se podría errar una vez, pagándose fuertes multas por ello, pero repetirlo hubiese sido imperdonable para todos aquellos colectivos que habían hecho de la presa en el mar una de sus principales fuentes de ingreso, bien para enriquecerse o, simplemente, para subsistir modestamente.

\section{Conclusiones}

Desde nuestra perspectiva, el interés del estudio de la Escuadra de Mallorca es doble. Ilustra, una vez más, las dificultades de la monarquía hispá-

57. En un acta notarial firmada el 11 de noviembre de 1680 se hace referencia a tal solicitud, indicándose que dichos fondos cubrirían «tanto la satisfacción de lo restituido a los franceses como lo gastado para la armazón de Su Real Orden» (ARM. S-1000, f. 18).

58. Nos consta que el 29 de octubre del mismo año se habían concedido 36.666 reales de a ocho: la tercera parte del gasto estimado por el Consejo de Guerra (ACA. Consejo de Aragón, legajo 999).

59. López Nadal (1988), p. 81.

60. A efectos jurídicos, se fijó el día 15 de agosto para su entrada en vigor (Utrera y Cruz, 1999), p. 48.

61. En los Archives du Ministeres des Affaires Etangêres (Correspondance Politique, Espagne), vol. 69, p. 270 se halla una relación de los navíos capturados tras la firma de la Tregua de Ratisbona. 
nica para defender con la Escuadra Real los territorios del imperio. Así mismo, ejemplifica la importancia que conforme avanzó el siglo XVII, y en particular durante el reinado de Carlos II, se otorgó a la institución corsaria para auxiliar a las marinas oficiales. Desde esta perspectiva, se entiende que la Escuadra de Mallorca (del mismo modo que otras flotas de características similares organizadas en distintos territorios) pueda ser considerada como una empresa militar en beneficio de la Corona. Sin embargo, más allá de este interés, no hay duda de que los privados, y en particular los mercaderes y algunos miembros del brazo noble, vieron en la sublevación de Mesina, como en muchos otros enfrentamientos bélicos, una oportunidad de negocio rápido que, dado que ya poseían los medios necesarios (barcos, dinero en metálico y experiencia previa), podía resultarles lucrativa. Por ello no dudaron, auspiciados por los sucesivos llamamientos reales a ejercer el corso y dada la posibilidad de ascenso social que en la época posibilitaba esta actividad, en preparar algunas de las naves con las que venían comerciando, e incluso mandar construir nuevos barcos, para involucrarse en el negocio. Una oportunidad que, aunque se sabía perentoria, auguraban que les reportaría ganancias de forma más rápida que el comercio convencional, sobre todo teniendo en cuenta los pingües beneficios que había proporcionado al corso isleño la intervención en la revuelta catalana.

Con este objetivo, y del mismo modo que sucedía con los negocios marítimos en general, un grupo de inversores principales (los mercaderes Juan Ballester, Juan Bautista Suñer, Gabriel, Agustín Antonio y Miguel Alex Cortés y los nobles señores Ramón Despuig y Juan Miguel Sureda) se pusieron al mando de la iniciativa e involucraron en el negocio a otros inversores secundarios (en total cuarenta y siete) para financiar la empresa. Los principales armadores se comprometieron ante notario a entregar a los respectivos capitanes de cada embarcación las cantidades acordadas y a repartir los futuros beneficios en función de las sumas aportadas. Posteriormente, dichos capitanes se responsabilizarían ante el representante real de abastecer las naves de todo lo necesario, pagar los salarios, conducir las presas a puerto, gestionar su venta y repartir los beneficios siguiendo, como se refleja en los contratos, los usos y costumbres propios de los «buenos corsarios». ${ }^{62}$ Así mismo, dado que era la Corona, y en su nombre el capitán general de Mallorca, quien propiciaba el negocio, y al fin y al cabo auspiciaba el armamento con una finalidad de servicio público, era esta quien fijaba las reglas del juego en un documento público en el que se estipulaba, como hemos visto, la composición y la capacidad de la flota, la tripulación, la fecha de partida y el punto de encuen-

62. Una expresión que si bien puede resultar un tanto ambigua, entendemos que hace referencia, como en tantos otros ámbitos, a un código de conducta no necesariamente escrito, pero conocido por todas las partes que intervenían en el negocio. 
tro con la Armada Real, la cantidad con que la Corona contribuiría a la puesta en marcha de las escuadras y los plazos en que dichas cantidades deberían ser abonadas.

En este caso concreto, hemos analizado de manera pormenorizada los dos contratos en los que se fijaban las condiciones a seguir tanto por parte de la Corona como de los particulares. No obstante, hemos subrayado que a pesar del elevado número de cláusulas y de la minuciosidad con que se especifican algunos detalles, no todas se cumplieron. A veces por razones relacionadas con las incertidumbres propias de este tipo de empresas o de la época preindustrial en general, pero otras - en el caso del segundo contrato- porque el representante real, una vez ya realizadas las inversiones previas, se excusó en que el porte y la calidad de las embarcaciones dispuestas no tenían la capacidad suficiente para oponerse al enemigo. Un cambio de parecer que a nuestro entender tuvo que ver, sobre todo, con la voluntad de ahorrar gastos a las arcas reales y con el convencimiento de que los armadores, después de las inversiones realizadas, no dudarían en llevar adelante su cometido pues, en su momento, como también hemos visto, el mismo virrey (Juan Francisco Cebrián, conde de Fuenclara) se había comprometido personalmente en la empresa invirtiendo una cantidad nada despreciable (1.360 libras), que resulta difícil entender que hubiera arriesgado si ciertamente no veía clara la viabilidad del servicio.

En cualquier caso, el cambio de opinión del representante real añade incertidumbre a una empresa que, por su propia naturaleza, debería asumir riesgos de todo tipo que acabarían provocando, finalmente, su desmembración, pues, si bien la Escuadra de Mallorca cumplió con éxito su objetivo de auxiliar a la flota real en Mesina y, a finales de 1678, algunas sus embarcaciones acompañaron incluso a la Escuadra del marqués de Villafiel hasta Galicia con el objetivo de hibernar en la región y trasladar parte de los efectivos a Flandes, ${ }^{63}$ desde el punto de vista económico, y sobre todo a medio plazo, la empresa resultó ser ruinosa. Y ello, a pesar, como también hemos visto, de que con la captura de una sola embarcación (La Nueva Jerusalén) se amortizaran todos los gastos de la segunda expedición. Con todo, la causa no estuvo relacionada ni con los riesgos propios del mar y la guerra ni con el escaso porte y capacidad de la flota, sino con otra de las múltiples incertidumbres a las que a menudo se enfrentaban las empresas preindustriales en general y las

63. En un artículo sobre el papel de Galicia en la última fase del imperio se recoge la noticia en relación con el traslado de dos convoyes que salieron de Vigo en 1680. El primero estaba formado por los navíos de la armada flamenca y el segundo, que salió de dicho puerto el 22 de septiembre, por dos de las unidades de la armada del Mar Océano. Entre estas últimas se encontraban, precisamente, varias embarcaciones de la Escuadra de Mallorca que habían operado en Mesina: la Concepción, el patache San Antonio y la nave Santa Teresa (Saavedra, 2011), pp. 245-246. 
marítimas en particular: las asimetrías informativas y la imposibilidad de que en aquella ocasión tuvieron los armadores isleños de utilizarlas a su favor.

Los corsarios mallorquines siguieron capturando mercantes franceses un año y medio después de que Francia y España hubieran firmado la Paz de Nimega (19 de agosto de 1678) porque, como explicaba el armador Juan Ballester, en Mallorca las paces no se hicieron públicas hasta el mes de marzo de $1680 \mathrm{y}$, en consecuencia, los corsarios decían no tener conciencia de haber realizado capturas de forma ilegal; un argumento ciertamente poco creíble. No obstante, lo más paradigmático es que con las paces ya establecidas, el propio monarca continuó firmando reales órdenes incentivando el armamento de nuevos corsos sin reparar en las consecuencias que de ello podrían derivarse. Desde nuestro punto de vista, una prueba más de la descoordinación de las instituciones responsables de la defensa naval durante la última fase del imperio. Lo que ayuda a entender, en definitiva, el cambio de estrategia posterior de los inversores, tanto de los miembros del brazo noble (que después de la Paz de Nimega priorizarán las inversiones en tierras y censos) como del capital mercantil que reorientará progresivamente sus negocios intentando asegurar «en tierra» los beneficios obtenidos en el mar.

\section{Siglas y abreviaturas más utilizadas:}

ACA (Archivo de la Corona de Aragón)

ACV (Archivo Vivot), ARM (Archivo del Reino de Mallorca)

BSAL (Butlletí de la Societat Arqueològica Lul-liana)

PN (Protocolos Notariales). 


\section{Apéndice}

CUADRO 8 - Relación nominal y extracción socioprofesional de los inversores de la Escuadra (1674-1677)

\begin{tabular}{|c|c|c|c|c|c|c|c|}
\hline \multirow{2}{*}{ Nombre } & \multirow{2}{*}{$\begin{array}{l}\text { Estatus/ } \\
\text { Profesión }\end{array}$} & \multirow{2}{*}{$\begin{array}{l}\text { Arma- } \\
\text { mentos }\end{array}$} & \multicolumn{3}{|c|}{ Cantidad invertida } & \multirow{2}{*}{$\begin{array}{c}\text { Cantidad } \\
\text { invertida } \\
\text { dineros }\end{array}$} & \multirow{2}{*}{$\%$} \\
\hline & & & Libras & Sueldos & Dineros & & \\
\hline Juan Ballester & Mercader & 7 & 25.082 & 11 & 16 & 6.019 .828 & $18,75 \%$ \\
\hline Juan Bautista Suñer & Mercader & 9 & 24.006 & & & 5.761 .440 & $17,95 \%$ \\
\hline Ramón Despuig & Noble & 10 & 18.808 & 19 & 5 & 4.514 .153 & $14,06 \%$ \\
\hline Juan Miguel Sureda & Noble & 10 & 13.437 & 27 & 18 & 3.225 .222 & $10,05 \%$ \\
\hline $\begin{array}{l}\text { Gabriel Cortés, de } \\
\text { Francisco }\end{array}$ & $\begin{array}{l}\text { Mercader judío } \\
\text { converso }\end{array}$ & 9 & 8.408 & 5 & 14 & 2.017 .994 & $6,29 \%$ \\
\hline $\begin{array}{l}\text { Agustín Antonio y Miguel } \\
\text { Alex Cortés }\end{array}$ & Mercaderes & 9 & 8.117 & 16 & 8 & 1.948 .280 & $6,07 \%$ \\
\hline Pedro Flexes & Capitán & 8 & 7.989 & 14 & 2 & 1.917 .530 & $5,97 \%$ \\
\hline $\begin{array}{l}\text { Pablo Delayet y } \\
\text { compañía }\end{array}$ & Mercaderes & 1 & 3.399 & 15 & 6 & 815.946 & $2,54 \%$ \\
\hline Cristóbal Garcías & Herrero & 10 & 2.877 & 17 & & 690.684 & $2,15 \%$ \\
\hline Francisco Desbrull & Noble & 3 & 2.798 & 13 & 4 & 671.680 & $2,09 \%$ \\
\hline Conde de Fuenclara & Virrey & 2 & 2.492 & 32 & 12 & 598.476 & $1,86 \%$ \\
\hline Jaime Canals & Capitán & 7 & 2.239 & 35 & 8 & 537.788 & $1,68 \%$ \\
\hline José Cordilla & Capitán & 2 & 1.603 & 5 & 8 & 384.788 & $1,20 \%$ \\
\hline Jaime Ballester & Capitán & 2 & 1.500 & & & 360.000 & $1,12 \%$ \\
\hline Jerónimo Campaner & Mercader & 2 & 1.046 & 7 & 4 & 251.128 & $0,78 \%$ \\
\hline Bernardino Estarellas & Capitán & 5 & 865 & & & 207.600 & $0,65 \%$ \\
\hline Gabriel Xambó & Mercader & 1 & 700 & & & 168.000 & $0,52 \%$ \\
\hline $\begin{array}{l}\text { Juan Antonio Escardo y } \\
\text { Jacinto Blanco }\end{array}$ & Mercaderes & 7 & 650 & & & 156.000 & $0,49 \%$ \\
\hline Jerónimo Doms & Noble & 1 & 572 & 14 & 10 & 137.458 & $0,43 \%$ \\
\hline Pablo Delayet & Mercader & 4 & 538 & & & 129.120 & $0,40 \%$ \\
\hline Joanot de Sala & Noble & 1 & 500 & & & 120.000 & $0,37 \%$ \\
\hline Juan Crespí & Farmacéutico & 5 & 490 & & & 117.600 & $0,37 \%$ \\
\hline $\begin{array}{l}\text { Gabriel Gartany y } \\
\text { Sebastian Salom }\end{array}$ & Boteros & 2 & 487 & 12 & 10 & 117.034 & $0,36 \%$ \\
\hline Gaspar de Puigdorfila & Noble & 2 & 465 & & & 111.600 & $0,35 \%$ \\
\hline Bernardino Estarellas & Capitán & & 453 & 6 & 8 & 108.800 & $0,34 \%$ \\
\hline Bernat Suñer & Capitán & 2 & 453 & & & 108.720 & $0,34 \%$ \\
\hline Antonio de Arabí & Noble (Ibiza) & 1 & 434 & 3 & 2 & 104.198 & $0,32 \%$ \\
\hline
\end{tabular}

(Continúa en la página siguiente) 


\begin{tabular}{|c|c|c|c|c|c|c|c|}
\hline \multirow{2}{*}{ Nombre } & \multirow{2}{*}{$\begin{array}{l}\text { Estatus/ } \\
\text { Profesión }\end{array}$} & \multirow{2}{*}{$\begin{array}{l}\text { Arma- } \\
\text { mentos }\end{array}$} & \multicolumn{3}{|c|}{ Cantidad invertida } & \multirow{2}{*}{$\begin{array}{c}\text { Cantidad } \\
\text { invertida } \\
\text { dineros }\end{array}$} & \multirow{2}{*}{$\%$} \\
\hline & & & Libras & Sueldos & Dineros & & \\
\hline Juan Malia & Farmacéutico & 5 & 400 & & & 96.000 & $0,30 \%$ \\
\hline Jerónimo Ballester & Mercader & & 400 & & & 96.000 & $0,30 \%$ \\
\hline María Montero & Noble (Ibiza) & 3 & 396 & & & 95.040 & $0,30 \%$ \\
\hline Francesc Pomar & Mercader & 1 & 300 & & & 72.000 & $0,22 \%$ \\
\hline Miguel Juan Fuster & Mercader & 1 & 275 & 13 & 14 & 66.170 & $0,21 \%$ \\
\hline Damián Más & Farmacéutico & 1 & 270 & & & 64.800 & $0,20 \%$ \\
\hline Nicolás Santacilia & Noble & 1 & 265 & 16 & 8 & 63.800 & $0,20 \%$ \\
\hline Marco Antonio Net & Mercader & 2 & 200 & & & 48.000 & $0,15 \%$ \\
\hline Guillem Barceló & Farmacéutico & 1 & 172 & & & 41.280 & $0,13 \%$ \\
\hline Bartolomé Sard & Carpintero & & 132 & 14 & & 31.848 & $0,10 \%$ \\
\hline Sebastián Llopis & Artesano & 1 & 125 & & & 30.000 & $0,09 \%$ \\
\hline Jacinto Blanco & Mercader & 1 & 108 & 6 & & 25.992 & $0,08 \%$ \\
\hline Antonio Dameto & Capitán & 2 & 100 & & & 24.000 & $0,07 \%$ \\
\hline Esteva Jaume & Carpintero & 1 & 90 & & & 21.600 & $0,07 \%$ \\
\hline Juan Servera & Notario & 1 & 76 & 14 & & 18.408 & $0,06 \%$ \\
\hline Cristóbal Seguí & Escribano & 1 & 25 & & & 6.000 & $0,02 \%$ \\
\hline Total & & 144 & 133.742 & 314 & 157 & 32.102 .005 & $100 \%$ \\
\hline
\end{tabular}

Fuente: Elaboración propia a partir de los protocolos indicados (ARM PS 994-997) en los que figuran las cantidades invertidas por cada socio en cada una de las embarcacions. Véanse para las inversiones en cada navío en particular Cirera (1942), López Nadal (2006) y Llompart, Morey y López (2016)

\section{BIBLIOGRAFÍA}

Aguiló Femenias, M. (2016). Una aproximación a la empresa familiar a partir del estudio de un conjunto de familias pertenecientes al colectivo judeo-converso: (Mallorca 18001950). Tesis doctoral leída en el Departamento de Economía Aplicada de la UIB.

Aguiló, M.; Morey, A. (2016). «Professional specialisation and ethnic minorities. The example of the Mallorcan judeo-converso (18th-20th centuries)». Journal Socio-Economic Analysis, vol. 8, pp. 114-124.

Atti Del Convegno Storico Internazionale (1979). La Rivolta di Messina (16741678 ) e il mondo mediterraneo nella sconda metà del Siecento. Consenza.

AzCÁrraga Bustamante, J. L. (1950). El corso marítimo: concepto, justificación e historia. Madrid: CSIC.

BiBILONI, A. (1992). Mercaders i navegants a Mallorca durant el segle XVII. L'oli com indicador del comerç mallorquí. Palma: El Tall.

- 1995. El comerç exterior de Mallorca. Homes, mercats i productes d'intercanvi (16501720). Palma: El Tall. 
Bono, S. (1993). Corsari nel Mediterraneo. Crisitiani e musulmani fra guerra, schiavitù e comercio. Milán: Mondadori.

Bournaz, V. A. B. (1994). Le Lys, Le Croissant \& La Méditerranée (à l'Epoque Moderne). Túnez.

BRAUdel, F. (1976). El Mediterráneo y el mundo mediterráneo en la época de Felipe II. México: FCE.

BRomLey, J.S.(1987). Corsairs and navies 1660-1760. Londres.

Bunes Ibarra, M. A. (2006). «La defensa de la cristiandad; las armadas en el Mediterráneo en la Edad Moderna», Cuadernos de Historia Moderna. Anejos, vol. 5, pp. 77-99.

Cirera Prim, J. (1942). «Escuadra de Mallorca en corso en el siglo XVII. Expediciones de Pedro Flexas y otros capitanes en el bloqueo de Mesina». BSAL, vol. 28, pp. 353-388.

Contreras Gay, J. (2003). «La reorganización militar en la época de la decadencia española (1640-1700)». Millars, vol. 26, pp. 131-154.

Crowhurst, P. (1987). «Guerre de Course et "Privateering": vers une étude comparative». En: Guerres et Pai, 1660-1815. Vincennes, pp. 311-322.

Deyá BauzÁ, M. J. (2010). «Repercussions del Tractat dels Pirineus a les Illes Balears». En: Tractat dels Pirineus a l'Europa del segle XXI, un model en construcció?: actes del congrés Barcelona-Perpinyà, 17-20 de juny de 2009. Barcelona: Generalitat de Catalunya, Departament de Cultura i Mitjans de Comunicació, Museu d'Història de Catalunya.

EARle, P. (2006). The Pirates War. Londres: Macmillan.

Espino López, A. (1999). Catalunya durante el reinado de Carlos II. Política y guerra en la frontera catalana, 1679-1697. Barcelona: Bellaterra.

FAJARnÉs, E. (1897). «Apresamiento de la nave Santa Cruz, Capitana de Mallorca (1683)». $B S A L, \mathrm{n} .^{\circ} 7, \mathrm{p} .190$.

Fernández Almagro, M. (1941). Política naval de la España moderna y contemporánea. Madrid.

Fernández Duro, C. (1972). La Armada española desde la unión de los reinos de Castilla y de Aragón. Madrid: Museo Naval, vol. 6.

Fontenay, M. (1986). «Los fenómenos corsarios en la "periferización” del Mediterráneo en el siglo Xviı». En: Pérez Picazo, M. T.; Lemeunier, G.; Segura, P. (eds.), Desigualdad y dependencia. La periferización del Mediterráneo occidental (ss. XII-XIX). Murcia, pp. 116-120.

- 1988. «La place de la course dans l'economie portuaire: l'exemple de Malte et des ports barberesques». Annales, Economies, Sociétés, Civilisations, n. ${ }^{\circ}$ 6, pp. 1321-1347.

Fontenay, M.; Tenenti, A. (1975). «Course et piraterie méditerranéennes: de la fin du Moyen Age au debut du Xxe siècle». En: XVe Colloque Internacional d'Historie Maritime, París, vol. 1, pp. 78-126.

Guevara, J. R. (2006). «El corso en el País Vasco del siglo XVI». Itsas Memoria. Revista de Estudios Marítimos del País Vasco, n. ${ }^{\circ}$ 5, pp. 245-278. 
Linon-Chipon, S.; Requemora, S. (2002). «Les tyrans de la mer: pirates, corsairs et flibustiers». París: Presse de l'Université Paris-Sorbonne, pp. 83-98.

López NADAL, G. (1978). «La participació del cors mallorquí a la desfeta de la revolta de Catalunya, 1638-1655». BSAL, n. ${ }^{\circ} 828-829$, pp. 246-272.

- (1979). «Competència entre el Consell d'Aragó i el Consell de Guerra pels judicis de les captures de cors a Mallorca. El cas de la presa "La Nueva Hierusalem"». Fontes Rerum Balearium, n. ${ }^{\circ}$ 3, pp. 203-226.

- (1981). «Sobre la revolta catalana i Mallorca». BSAL, n. ${ }^{\circ}$ 835, pp. 491-494.

- (1983). «The Majorcan privateers and the Catalan Revolt». The Mariner's Mirror, n. ${ }^{\circ} 69 / 3$, pp. 291-299.

- (1986). El corsarisme mallorquí a la Mediterrània occidental: 1652-1698. Un comerç forçat. Palma: Conselleria d'Educació i Cultura del Govern Balear.

- (1987). «Actividades financieras de los chuetas en la segunda mitad del siglo XVII. Armamentos en corso y seguros marítimos». En: AA.VV, A face not turned to the Wall. Essays an Hispania themes for gareth. University of Leeds, pp. 111-136.

- (1993a). «Contribution à l'étude du revenu dans un système commercial non conventionnel: la course europeenne en Méditerranée durant le XVIIe et le XVIIIe siècles». Studia Historiae Oeconomica, n. ${ }^{\circ}$ 20, pp. 19-29.

- (1993b). «El corsarisme com a institució marítima: els judicis de preses a Mallorca (1654-1687)». Pedralbes. Revista d'Història Moderna, n. . 13, pp. 93-102.

- (1995). «Mallorca y la rebelión de Mesina (1674-1678). Los contratos de la intervención isleña». Cuadernos de Historia Militar, n. ${ }^{\circ}$ 1, pp. 146-162.

- (1997). «Comer en el mar. Aspectos sobre el consumo alimenticio en la navegación mediterránea europea (ss. XVI-XVIII)». En: Cavaciocchi, S. (ed.), Alimentazione e nutrizione. Secc. XIII-XVIII. Atti della "Ventotessima Settimana di Studi (22-27 aprile $1996)$ de l'Istituto Internazionale di Storia Economica F. Datini. Florencia, pp. 527538.

- (1998a). «El corsarismo mallorquín después de la Paz de Nimega (1678-1684)». Estudis d'història econòmica, n. ${ }^{\circ} 15$, pp. 62-89.

- (1998b). «L'impost a les preses per mar: el quint reial». En: VI Jornades d'Estudis Històrics Locals. Fiscalitat estatal $i$ hisenda local (ss. XVI-XIX). Funcionament i repercussions socials. Palma: Institut d'Estudis Baleàrics, pp. 301-312.

- (1999). «Entre la cruz y la media luna. Consideraciones sobre las vinculaciones ineludibles de los dos mundos del Mediterráneo». En: Belenguer, E. (coord.), Felipe II y el Mediterráneo. Madrid: Sociedad Estatal para la Conmemoración de los Centenarios de Felipe II y Carlos V, vol. 3, pp. 409-425.

- (2006). «The Majorcan Squadron (1660-1684). Notes for a Study of Maritime Enterprise: supplying, financing and investment». En: Cavaciocchi, S. (ed.), Richezza del mare secc. XIII-XVIII. Atti della "Trentasettesima Settimana di Studi 11-15 aprile 2005. Florencia: Le Monnier, 2006, pp.727-760.

- (2009). «El capità Jaume Canals i els negocis de la mar». BSAL, n. ${ }^{\circ}$ 65, pp. 141-154. 
López, G.; Manera, C. (2000). «Minoría étnica y poder económico: la intervención de los chuetas de Mallorca en el comercio de Mallorca: 1650-1800». En: Cavaciochi, S. (ed.), Il ruolo económico delle minoranze in Europa. Seccoli XIII-XVIII. Florencia: Le Monnier, pp. 455-478.

MANerA, C. (1993). «Capital mercantil et critères d'investissement des commerçants de l'île de Majorque pendant le XvIIIeme siècle». Studia Historiae Oeconomica, n. ${ }^{\circ} 20$, pp. 106-118.

Martínez Ruiz, E. (2008). Los soldados del rey. Los ejércitos de la monarquía hispánica (1480-1700). Madrid: Actas.

Montaner, P. (1978). «Los caballeros de órdenes militares y el comercio en Mallorca durante los siglos XVI y XVII». BSAL, n. ${ }^{\circ} 828-29$, pp. 99-109.

- (1984). «Relaciones entre la nobleza comerciante mallorquina y los chuetas en vísperas de la Guerra de Sucesión». BSAL, n. ${ }^{\circ} 40$, pp. 255-271.

- (1987). «La estructura del brazo noble mallorquín bajo los Austrias». Estudis Baleàrics,.$^{\circ}$ 27, pp. 3-38.

- (1989). «Senyor a Mallorca: un concepte heterogeni». Estudis Baleàrics, n. o 34, pp. 5-35.

- (1990). Una conspiración filipista: Mallorca 1711. Palma: Guillermo Canals.

Montaner, P.; Le-Senne, A. (1979-1980). «Nobleza, comercio y corso en la Mallorca moderna: los "negocis per mar" de los Sureda». Mayurqa, n. ${ }^{\circ}$ 19, pp. 233-244.

Morey, A. (1992). «El patrimoni Vivot: alguns suggeriments sobre la seva formació». Estudis d'Història Econòmica, n. ${ }^{\circ} 1$, pp. 97-121.

- (2016). «Cors: famílies, patrimoni i vinculació de la terra a Mallorca». En: El Cors espanyol a la Mediterrània (1492-1830). Consell Insular d'Eivissa, Universitat de les Illes Balears, trabajo inédito.

- (2018a). «Nueva Planta, estrategias hereditarias e influencias mútuas entre las instituciones vinculares de Castilla y Aragón (1736-1836)». En: DEYÁ BAUZÁ (dir.). 1716: El final del sistema foral de la monarquia hispànica. Palma: Lleonard Muntaner, pp. 335-356.

- (2018b). «Pràctiques agràries i codis de conducta a les possessions mallorquines. Conrar “a ús i costum” (segles XVIII i XIX)». Recerques n 73, pp. 53-80.

Olesa Mundo, F. (1968). La organización naval de los estados mediterráneos y, en especial, de España durante los siglos XVI y XVII. Madrid, 2 vols.

Otero Lana, E. (1999). Los corsarios españoles durante la decadencia de los Austrias: el corso español del Atlántico peninsular en el siglo XVII (1621-1697). Madrid: Naval.

- (2006). «Los corsarios vascos en la Edad Moderna». Itsas Memoria. Revista de Estudios Marítimos del País Vasco, n. ${ }^{\circ}$ 5, pp. 193-227.

Pascual, A. (1989). «Para el estudio de las casas de aristócratas y mercaderes en la ciudad de Mallorca durante el siglo XVII». Estudis Baleàrics, n. ${ }^{\circ}$ 34, pp. 115-147.

Pennell, C.R. (ed.) (2001). Bandits at sea. A Pirates Reader. New York University Press.

Pi Corrales, M. (2001). «La armada del siglo XViı». En: AA. VV. Calderón de la Barca y la España del Barroco. Madrid, vol. 1, p. 13. 
- (ed.) (2006). «Armar y marear en los siglos modernos: XV-XVIII». Cuadernos de Historia Moderna, Anejo V, pp. 201-209.

Planas, N. (2011). «Navegar con rumbo. Actividad corsaria y sociedades mercantiles en un Mediterráneo "conectado" (s. XVII)». Memòries de la Reial Acadèmia Mallorquina d'Estudis Genealògics, Heràldics i Històrics, n. ${ }^{\circ}$ 21, pp. 79-101.

Pons Pons, J. (1996). Companyies i mercat assegurador a Mallorca (1650-1715). Palma: El Tall.

Ribot García, L. A. (1983). «El ejército de los Austrias. Aportaciones recientes y nuevas perspectivas». Pedralbes: revista d'història moderna, n. ${ }^{\circ}$ 3, pp. 89-126.

- (1995). «Las provincias italianas y la defensa de la monarquía». Manuscrits, n. ${ }^{\circ} 13$, pp. 97-122.

- (2002). La monarquía de España y la guerra de Mesina. Madrid: Actas.

Rodríguez Hernández, A. J. (2007). España, Flandes y la Guerra de la Devolución (1667-1668). Guerra, reclutamiento y movilización para el mantenimiento de los Países Bajos españoles. Madrid.

Ruiz Ibáñez, J. J.; Montojo Montojo, V. (1998). Entre el lucro y la defensa. Las relaciones entre la monarquía y la sociedad mercantil cartagenera. Comerciantes y corsarios en el siglo XVII. Murcia: Academia Alfonso X el Sabio.

SAAVEdRa VÁquez, M. C. (2006). «La formación de armadas y sus efectos sobre el territorio: el ejemplo de Galicia, 1580-1640». Cuadernos de Historia Moderna. Anejo V, pp. 55-76.

- (2011). «La decadencia militar del imperio español de los Austrias: algunas consideraciones a partir del caso gallego». Semata, vol. 23, pp. 229-251.

- (2013). «Política naval, corsarios y armadas en la Galicia Moderna». Minius, n. ${ }^{\circ}$ 21, pp. 87-115.

SAlvá, J. (1944). La Orden de Malta y las acciones navales españolas contra los turcos y berberiscos en los siglos XVI y XVII. Madrid.

Starkey, D. J.; De Moor, J.; Heslinga, V.E. (eds.) (1997). Pirates and Privateers. New perspectives on the War and Trade in the Eighteenth and Nineteenth Centuries. Liverpool University Press.

STORRS, Ch. (2003). «La pervivencia de la monarquía española bajo el reinado de Carlos II (1665-1700)». Manuscrits, n. ${ }^{\circ}$ 21, pp. 39-61.

Toussaint, A. (1978). Histoire des Corsaires. Presses Univesitaires de France.

Utera, C.; CRuz, D. (1999). Cronología de la historia de España. Madrid: Acento.

Vasallo, C. (1997). Corsairing to commerce. Maltese merchants in Eighteenth century Spain. Malta University Publishers

Vergé-Franceschi, M. ; Graziani, A. M. (2000). La guerre de course en Méditerranée. París: Sorbonne.

Zaouali, A. (2001). «Taifa dei Rais e Ordine dei Cavalieri di Santo Stefano: potere e rappresentazione nella città. Un approcio comparativo». En: Atti del Convengno L'Ordine di Santo Stefano e il Mare. Pisa, pp. 67-81. 


\title{
Privateering as a service to the Crown and a business opportunity for indi- viduals. The Mallorcan Squadron (1660-1684)
}

\begin{abstract}
The decline of the Spanish navy during the reign of Charles II lies at the core of the emergence of private fleets to aid the Royal Armada against the King's political enemies. The case of the Mallorcan Squadron, motivated by the Messina revolt (1674-1678), is an example of the convergence of general and private interests that was so frequent during the Modern Age. This article offers an overview of the functioning of the Mallorcan Squadron, and looks at the following main aspects in greater depth: the financing of the enterprise, the costs of arming and the social and professional background of the investors, the conditions or rules of play to be followed by individuals and the crown in the course of the service, the nature of the expenses and profits, the procedure for division of the profits, and the risk of information asymmetry for the privateering businesses.
\end{abstract}

KEYWORDS: Mallorcan Squadron, privateering companies, Messina Revolt, Economic history of enterprise, seventeenth century

JEL CODES: N44, N84, O17

\section{El corso como servicio a la Corona y oportunidad de negocio para los par- ticulares. La Escuadra de Mallorca (1660-1684)}

\section{RESUMEN}

La decadencia naval española durante el reinado de Carlos II está en la base del surgimiento de armadas particulares para auxiliar a la Armada Real contra los enemigos políticos del rey. El caso de la Escuadra de Mallorca con motivo de la sublevación de Mesina constituye un ejemplo de la confluencia entre el interés general y particular tan frecuente durante la Edad Moderna. En este artículo se ofrece una visión de conjunto sobre el funcionamiento de la Escuadra, a la vez que se profundiza en los siguientes aspectos: la financiación de la empresa, los costes del armamento y la extracción socioprofesional de los inversores, las condiciones o reglas del juego a seguir por los particulares y la Corona en el transcurso del servicio, la tipología de los gastos y beneficios, la forma de proceder en el reparto de los beneficios y el riesgo de las asimetrías informativas para los negocios corsarios.

Palabras Clave: Escuadra de Mallorca, compañías corsarias, Sublevación de Mesina, historia económica de la empresa, siglo XVII

Códigos JEL: N44, N84, O17 